\title{
Agent Affecting Organs of Special Senses
}

National Cancer Institute

\section{Source}

National Cancer Institute. Agent Affecting Organs of Special Senses. NCI Thesaurus. Code $C 78283$.

An agent that exerts a physiologic effect on the organs of special senses, including the eyes, ears and nose. This category includes otic, nasal and ophthalmic agents. 